\title{
1 One-step preparation of 2,3,6-tricarboxy cellulose
}

2

3

4

5

6

$7 \quad *$ Corresponding author. Tel: +813 5841 5538; Fax: +81 358415269.

8 1-1-1 Yayoi, Bunkyo-ku, Tokyo 113-8657, Japan

$9 \quad$ E-mail address: aisogai@mail.ecc.u-tokyo.ac.jp (A. Isogai).

Satoshi Takaichi, Ryoya Hiraoki, Toru Inamochi, Akira Isogai*

Department of Biomaterial Sciences, The University of Tokyo, Tokyo 113-8657, Japan

\section{ABSTRACT}

Water-soluble sodium 2,3,6-tricarboxylate cellulose (NaTCC) or sodium mesotartarate/monohydrated glyoxilate alternating co-polyacetal was prepared from regenerated cellulose in a yield of $82 \%$ by one-step oxidation with catalytic amounts of 2azaadamantane $\mathrm{N}$-oxyl (AZADO), $\mathrm{NaBr}$, and excess $\mathrm{NaOCl}$ in water at room temperature under alkaline conditions. The AZADO-oxidized product was shown to have an almost homogeneous NaTCC chemical structure by its ${ }^{1} \mathrm{H}$ - and ${ }^{13} \mathrm{C}-\mathrm{NMR}$ spectra. The weight- and number-average molecular masses of the obtained NaTCC were 10700 and 7000. When AZADO-mediated oxidation was applied to softwood bleached kraft pulp, a water-soluble oxidized product was obtained. However, it had a more heterogeneous chemical structure showing that the complete oxidation of the $\mathrm{C} 2, \mathrm{C} 3$, and $\mathrm{C} 6$ hydroxyls to carboxyls is difficult to achieve in native cellulose.

Keywords: Azaadamantane $N$-oxyl; AZADO; mesotartaric acid/hydrated glyoxilic acid alternating co-polyacetal; size-exclusion chromatography; 2,3,6-tricarboxy cellulose

\section{Introduction}

The preparation of water-soluble polymers from water-insoluble cellulose, which is the most abundant and reproducible natural polymer on earth, is of significance for the applications of bio-based polymers as stable thickeners, emulsion stabilizers, and other 
additives. Sodium carboxymethyl cellulose, methyl cellulose, and hydroxypropyl and hydroxyethyl celluloses are categorized as typical water-soluble cellulose derivatives, which are prepared by the partial etherification of cellulose hydroxyls under alkaline conditions with or without $i$-propanol, and they are used in various commodity and industrial fields (Heinze, 1998).

The formation of carboxyl groups at the $\mathrm{C} 2, \mathrm{C} 3$, or C6 position of the glucosyl unit of cellulose by oxidation to prepare water-soluble or water-swellable products has been studied at industrial and laboratory levels. Oxycelluloses have been produced from rayon fiber nits by soaking in a $\mathrm{N}_{2} \mathrm{O}_{4}$-containing chloroform solution. They are used as hemostatic fabrics in medical fields (Martina, Kateřina, Miloslava, Jan, \& Ruta, 2009). Some C6-primary hydroxyls are converted to C6-carboxyls during $\mathrm{N}_{2} \mathrm{O}_{4}$ oxidation although side reactions are inevitable (Yackel \& Kenyon, 1942; Nevell, 1951). Water-soluble 2,3-dicarboxy cellulose can be prepared from 2,3-dialdehyde cellulose by oxidation with $\mathrm{NaOCl}_{2}$ in water at $\mathrm{pH} 4-5$ (Maekawa \& Koshijima, 1990; Heinze, 1998; Kim, Kuga, Wada, Okano, \& Kondo, 2000).

Water-soluble C6-carboxy cellulose, cellouronic acid, or $\beta-(1 \rightarrow 4)$-polyglucuronic acid with an almost homogeneous chemical structure has been prepared from regenerated cellulose by 2,2,6,6-tetramethylpiperidine-1-oxyl radical (TEMPO)-mediated oxidation in water under weakly acidic or alkaline conditions (Isogai \& Kato, 1998; Tavernier, Delattre, Petit, \& Michaud, 2008; Hirota, Tamura, Saito, \& Isogai, 2009; Isogai, Saito, \& Fukuzumi, 2011). Because of the four bulky methyl groups at the $\mathrm{C} 2$ and $\mathrm{C} 6$ positions of TEMPO, TEMPOmediated oxidation can be used to convert the C6-primary hydroxyls of cellulose to sodium C6-carboxylates almost position-selectively. Even though extensive depolymerization of cellulose molecules is unavoidable in TEMPO-mediated oxidation under alkaline conditions (Shibata \& Isogai, 2003), oxidation using 4-acetamido-TEMPO in water at $\mathrm{pH} 4.8$ can be used to control depolymerization to some extent, thus providing water-soluble cellouronic acids with higher molecular masses.

2,3,6-Tricarboxy cellulose or mesotartaric acid/monohydrated glyoxilic acid alternating co-polyacetal (Fig. 1) was first prepared by the three-step oxidation of cellulose with $\mathrm{N}_{2} \mathrm{O}_{4}$, $\mathrm{NaIO}_{4}$, and $\mathrm{HClO}_{2}$ (Head, 1948). The two-step oxidation of cellulose with $\mathrm{NaIO}_{4}$ and $\mathrm{N}_{2} \mathrm{O}_{4}$ to prepare TCC was then reported as a resource for the provision of tartaric acid, a hemostatic agent and a chelator of metallic ions (Hearon, Cheng, \& John, 1975; Sinha \& Vasudevan, 1984; Bashmakov, Dorosinets, Lukashevich, Mazanik, Tikhonova, \& Skripka, 2002).

Although the preparation of TCC from cellulose has been already reported, no detailed information concerning the chemical structures of the obtained TCCs using, e.g., NMR, have 
been reported. Moreover, two- or three-step reactions using toxic or explosive reagents such as gaseous $\mathrm{N}_{2} \mathrm{O}_{4}, \mathrm{NaIO}_{4}$, and chloroform have been required to prepare TCCs.

In this paper, we report a novel one-step preparation method for the sodium salt of TCC (NaTCC) or sodium mesotartarate/hydrated glyoxilate alternating co-polyacetal (Fig. 1) from regenerated and native celluloses. 2-Azaadamantane $N$-oxyl (AZADO) was used as a catalyst in water under alkaline conditions. AZADO is a stable nitroxyl radical and has the ability to oxidize primary and secondary alcohols to carboxyl and carbonyl groups, respectively, under aqueous conditions (Shibuya, Tomizawa, Suzuki, \& Iwabuchi, 2006). In our previous study, an $\mathrm{AZADO} / \mathrm{NaBr} / \mathrm{NaOCl}$ system was applied to native wood cellulose to prepare AZADOoxidized celluloses with a sufficient amount of sodium C6-carboxylate groups, which were then converted to AZADO-oxidized cellulose nanofibrils individually dispersed in water by gentle mechanical disintegration treatment (Takaichi \& Isogai, 2013). We found during the study that almost all the C6-primary hydroxyls and also small amounts of the C2/C3 hydroxyls present on the crystalline cellulose microfibril surfaces of the wood cellulose were converted to C6-carboxyls and ketones, respectively. In this study, therefore, the AZADO/NaBr $/ \mathrm{NaOCl}$ oxidation system with excess $\mathrm{NaOCl}$ was applied to regenerated and native celluloses to prepare NaTCC, and the chemical structures and molecular masses of the oxidized products obtained were studied by NMR, size-exclusion chromatography, and other analysis methods.

\section{Materials and methods}

\subsection{Materials}

Bemliese $^{\circledR}$ (Asahi Chemicals Co., Ltd., Tokyo, Japan) produced from cotton linters using a cuprammonium solvent system was used as a regenerated cellulose sample. A never-dried softwood bleached kraft pulp (Nippon Paper Industries, Tokyo, Japan), which had a $\sim 90 \% \alpha$ cellulose content, was used as a native cellulose sample. The pulp was soaked in a dilute aq. $\mathrm{HCl}$ solution at room temperature for $0.5 \mathrm{~h}$, and then washed repeatedly with water via filtration. AZADO, sodium bromide, $1.86 \mathrm{M}$ sodium hypochlorite solution, and other chemicals and solvents were of laboratory grade (Wako Pure Chemicals, Tokyo, Japan) and used without further purification.

\subsection{Oxidation of regenerated cellulose}


Regenerated cellulose ( $1 \mathrm{~g})$ was suspended in distilled water $(100 \mathrm{~mL})$ containing sodium bromide $(0.1 \mathrm{~g})$ and AZADO $(15.3 \mathrm{mg}, 0.1 \mathrm{mmol} / \mathrm{g}$-cellulose) in a beaker $(200 \mathrm{~mL})$. The AZADO-mediated oxidation was started by adding the $\mathrm{NaOCl}$ solution $(22 \mathrm{~mL}, 40 \mathrm{mmol})$ to the cellulose slurry at room temperature under continuous stirring. The $\mathrm{pH}$ of the slurry was maintained at 10 by the continuous addition of a $1 \mathrm{M} \mathrm{NaOH}$ solution using a $\mathrm{pH}$ stat for $6 \mathrm{~h}$. Then, the slurry was transferred to an Erlenmeyer flask with an airtight stopper, and the mixture was continuously stirred for $16 \mathrm{~h}$ without $\mathrm{pH}$ control. Sodium thiosulfate pentahydrate $\left(\sim 2.5 \mathrm{~g}, \sim 10 \mathrm{mmol} \mathrm{Na} 2 \mathrm{~S}_{2} \mathrm{O}_{3}\right)$ was added to the transparent solution obtained to quench the oxidation. The crude oxidized product was purified by dialysis against water for 4 days using a dialysis membrane with a cut-off molecular weight of 12000 . Then, $0.05 \mathrm{M}$ $\mathrm{NaOH}$ was added to the purified product solution to adjust the $\mathrm{pH}$ to 7.8 followed by freeze drying. This process was carried out to convert free carboxyls in the product to sodium carboxylate groups.

\subsection{Oxidation of native cellulose}

Never-dried softwood bleached kraft pulp (1 g) was suspended in distilled water (100 $\mathrm{mL}$ ), and oxidized using the $\mathrm{AZADO} / \mathrm{NaBr} / \mathrm{NaOCl}$ system with a slight modification compared with the above-mentioned procedure. The amount of $\mathrm{NaOCl}$ solution added during the initial oxidation stage was $13.4 \mathrm{~mL}(25 \mathrm{mmol})$ and then a further $8 \mathrm{~mL}(15 \mathrm{mmol}) \mathrm{NaOCl}$ solution was added to the reaction mixture in the Erlenmeyer flask after the initial oxidation period of $6 \mathrm{~h}$ and before being tightly sealed with a stopper. Sodium thiosulfate pentahydrate $\left(\sim 2.5 \mathrm{~g}, \sim 10 \mathrm{mmol} \mathrm{Na}_{2} \mathrm{~S}_{2} \mathrm{O}_{3}\right)$ was added to the translucent reaction mixture to quench the oxidation. The crude oxidized product was purified by dialysis against water for 4 days, and subsequently the solution was filtered through a cellulose ester membrane filter with a 0.05 $\mu \mathrm{m}$ pore size. Then, $0.05 \mathrm{M} \mathrm{NaOH}$ was added to the purified and transparent product solution to adjust the $\mathrm{pH}$ to 7.8 followed by freeze drying.

\subsection{Analyses}

The AZADO-oxidized products were dissolved in $\mathrm{D}_{2} \mathrm{O}$ and were subjected to ${ }^{1} \mathrm{H}$ and ${ }^{13} \mathrm{C}$ NMR analysis using an ALPHA-500 (JEOL, Japan) with 3-trimethylsilyl-2,2,3,3- $d_{4}$-propionic 
acid sodium salt (Aldrich, USA) as the internal standard. Quantitative ${ }^{13} \mathrm{C}$ NMR spectra were obtained using a gated decoupling method without a nuclear Overhauser effect (Wei \& Schweiger, 2010). The acquisition and delay times of the ${ }^{13} \mathrm{C}$ NMR measurement were 0.27 and $2.0 \mathrm{~s}$, respectively. The data accumulation times for the ${ }^{1} \mathrm{H}$ and ${ }^{13} \mathrm{C}$ NMR spectra were 32 and 25000, respectively. Heteronuclear single quantum coherence (HSQC) spectrum of the oxidized product was recorded according to a reported method (Kurita \& Isogai, 2010). Fourier transform infrared (FT-IR) spectra of the AZADO-oxidized products were recorded on a Jasco FT/IR-6100 spectrometer in transmission mode with $4 \mathrm{~cm}^{-1}$ resolution using the $\mathrm{KBr}$ disk technique. The carboxylate content of the products was determined using an electric conductivity titration method (Saito \& Isogai, 2004). The dried sample (0.04 g) was dissolved in water $(55 \mathrm{~mL})$, and $0.01 \mathrm{M} \mathrm{NaCl}(5 \mathrm{~mL})$ was added to the solutions. Then, $0.1 \mathrm{M} \mathrm{HCl}$ was added to the mixture to set the $\mathrm{pH} 1.8$. A $0.15 \mathrm{M} \mathrm{NaOH}$ solution was added at the rate of 0.1 $\mathrm{mL} / \mathrm{min}$ up to $\mathrm{pH} 11$ using a $\mathrm{pH}$ stat. The carboxylate content of the sample was determined from the conductivity and $\mathrm{pH}$ curves. Molecular mass parameters of the AZADO-oxidized products were measured using a size-exclusion chromatograph (SEC) furnished with a multiangle laser light-scattering (MALLS) detector (DAWN EOS, k=690 nm; Wyatt Technologies, USA). The oxidized products ( $1 \mathrm{mg}$ each) were dissolved in $0.1 \mathrm{M} \mathrm{NaCl}(1 \mathrm{~mL})$ to prepare $0.1 \mathrm{w} / \mathrm{v} \%$ solutions. A poly(hydroxymethacrylate) gel (SB-806MHQ, $8 \mathrm{~mm} \varphi \times 30 \mathrm{~cm}$, Shodex, Japan) was used as the SEC column. All the sample solutions and eluents were filtered beforehand through $0.45 \mu \mathrm{m}$ PTFE membranes (Millipore, USA). The MALLS cells and refractive index detector were kept at room temperature and $40{ }^{\circ} \mathrm{C}$, respectively. Detailed operation and measurement conditions of the SEC-MALLS are described elsewhere (Hirota et al., 2009; Fujisawa, Isogai \& Isogai, 2010; Homma, Isogai, Saito, \& Isogai, 2013; Watanabe, Habu, \& Isogai, 2013; Watanabe, Tamura, Fujisawa, Saito, Habu, \& Isogai, 2013; Hiraoki, Fukuzumi, Ono, Saito, \& Isogai, 2013; Watanabe, Tamura, Saito, Habu, \& Isogai, 2014). The specific refractive index increment $(d n / d c)$ of the AZADO-oxidized product prepared from regenerated cellulose, which was dried by freeze drying and the successive vacuum drying, was determined in a $0.1 \mathrm{M} \mathrm{NaCl}$ solution using an interferometric refractometer (Wyatt Technologies, USA), and the obtained value was $0.137 \mathrm{~mL} / \mathrm{g}$. This value was used for the calculation of molecular masses.

\section{Results and discussion}

\subsection{AZADO-mediated oxidation of regenerated and native celluloses}


The regenerated and native celluloses were oxidized using the AZADO/ $\mathrm{NaBr} / \mathrm{NaOCl}$ system with excess $\mathrm{NaOCl}$ in water at $\mathrm{pH} 10$ and at room temperature for $6 \mathrm{~h}$. Additional $16-\mathrm{h}$ reaction time was allowed without $\mathrm{pH}$ control under alkaline conditions. The regenerated cellulose/water slurry during the initial stage became a transparent solution because of oxidation showing that the water-insoluble regenerated cellulose became water soluble. For native cellulose, the slurry did not become a completely transparent solution but rather a translucent solution was obtained upon the AZADO-mediated oxidation (Fig. 2). Water solubility and ${ }^{13} \mathrm{C}$ NMR pattern simplicity of the oxidized celluloses prepared from regenerated and native celluloses under various conditions, which were carried out in preliminary experiments, are summarized in Table 1. Because a completely transparent solution could not be obtained for the native cellulose, the water-insoluble fraction present in small quantities in the AZADO-oxidized product was removed via filtration to obtain a watersoluble and transparent fraction. When the same wood cellulose was oxidized using the AZADO-mediated system under milder conditions to prepare AZADO-oxidized cellulose nanofibrils, the original fibrous morphology was found to be maintained during the oxidation (Takaichi \& Isogai, 2013). Thus, the addition of more $\mathrm{NaOCl}$ and a longer reaction time for the oxidation of wood cellulose provided an oxidized product that is different from those reported previously.

The water-soluble AZADO-oxidized regenerated and native celluloses with sodium counter ions that were obtained after purification had weight recovery ratios of 139 and $111 \%$, respectively, and carboxylate contents of 10.4 and $9.7 \mathrm{mmol} / \mathrm{g}$, respectively (Table 2). Sodium cellouronate or sodium $\beta-(1 \rightarrow 4)$-polyglucuronate with ideal chemical structures that were obtained from regenerated cellulose through TEMPO-mediated oxidation have a carboxylate content of $5.05 \mathrm{mmol} / \mathrm{g}$ (Isogai \& Kato, 1998; Hirota et al., 2009). Therefore, a higher amount of sodium carboxylate groups was present in the AZADO-oxidized celluloses compared with those of cellouronic acid, indicating that the C6-primary hydroxyls and also some of $\mathrm{C} 2$ and C3 hydroxyls were oxidized to carboxyls after the oxidation.

\subsection{Chemical structures of the AZADO-oxidized celluloses}

The FT-IR spectra of the water-soluble AZADO-oxidized celluloses are shown in Fig. 3. Both the oxidized celluloses prepared from the regenerated and native celluloses had similar patterns; significant amounts of carboxylate groups were present in the products and the $\mathrm{C}-\mathrm{H}$ 
groups originally present in the cellulose mostly disappeared.

Figure 4 shows the ${ }^{1} \mathrm{H}$ NMR spectra of the AZADO-oxidized celluloses. Two major signals were observed at $\sim 4.4$ and $\sim 4.9 \mathrm{ppm}$ for the product prepared from regenerated cellulose, and the signal peaks were located at 4.44 and $4.93 \mathrm{ppm}$. These signals are assigned to the $\mathrm{C} 4 / \mathrm{C} 5$ and $\mathrm{C} 1$ protons of NaTCC or sodium mesotartarate/monohydrated glyoxilate alternating co-polyacetal on the basis of their chemical shifts and signal areas. The ${ }^{1} \mathrm{H}$ NMR spectrum of the AZADO-oxidized native cellulose consisted of more complicated signals probably because of side reactions that occurred during the formation of NaTCC, and this is discussed later.

The ${ }^{13} \mathrm{C}$ NMR spectra of the AZADO-oxidized regenerated and native celluloses are shown in Fig. 5, and these were obtained using the quantitative mode. Four major signals were present at $82.5,103.4,176.6$, and $178.2 \mathrm{ppm}$ for the AZADO-oxidized regenerated cellulose, and these signals are assigned to the $\mathrm{C} 4 / \mathrm{C} 5, \mathrm{C} 1, \mathrm{C} 2$ and $\mathrm{C} 3 / \mathrm{C} 6$ carbons, respectively, of the sodium mesotartarate/glyoxilate alternating acetal dimer repeating units from their chemical shifts and signal areas, and the HSQC spectrum of the AZADO-oxidized regenerated cellulose (Fig. 6). Thus, NaTCC or sodium mesotartarate/monohydrated glyoxilate alternating co-polyacetal with an almost homogeneous chemical structure can be obtained from regenerated cellulose by $\mathrm{AZADO} / \mathrm{NaBr} / \mathrm{NaOCl}$ oxidation under the relatively harsh conditions used in this study. Because the carboxylate content of NaTCC with a completely homogeneous chemical structure is calculated to be $11.0 \mathrm{mmol} / \mathrm{g}$ from the molecular formula of the monomer unit, $\mathrm{C}_{6} \mathrm{H}_{3} \mathrm{O}_{8} \mathrm{Na}_{3}$, the AZADO-oxidized regenerated cellulose with a carboxylate content of $10.4 \mathrm{mmol} / \mathrm{g}$ can be regarded as an almost pure NaTCC (Table 2). However, the presence of small signals other than the four major signals observed in Fig. 5 indicates that some minor side reactions took place on the molecules during the oxidation.

When the AZADO-mediated oxidation was applied to the softwood bleached kraft pulp that was used as an example of native cellulose, a water-soluble oxidized product with a carboxylate content of $9.7 \mathrm{mmol} / \mathrm{g}$ was obtained after dialysis and subsequent filtration. However, both the ${ }^{1} \mathrm{H}$ and ${ }^{13} \mathrm{C}$ NMR spectra of the oxidized product showed more complicated patterns (Figs. 4 and 5). The ${ }^{13} \mathrm{C}$ NMR spectrum consisted of carbon signals from NaTCC and also from some other by-products at 70.0, 95.7, 102.2, 179.4, and $188.6 \mathrm{ppm}$. This product had a more heterogeneous chemical structure than that obtained from regenerated cellulose. Because native cellulose containing cellulose I is crystalline and it has molecular mass values much higher than that of the regenerated cellulose containing cellulose 
237 II, the latter is likely to have higher accessibility to oxidation than the former resulting in a difference in the chemical structure between the two AZADO-oxidized products.

\subsection{Molecular masses of AZADO-oxidized celluloses}

The AZADO-oxidized regenerated and native celluloses were dissolved in $0.1 \mathrm{M} \mathrm{NaCl}$, and subjected to SEC-MALLS analysis to determine their molecular masses (Fig. 7 and Table 2). The weight- and number-average degrees of polymerizations ( $D P_{\mathrm{w}}$ and $D P_{\mathrm{n}}$, respectively) were calculated from the corresponding molecular masses, assuming that the oxidized products had homogeneous NaTCC chemical structures. Both AZADO-oxidized celluloses had similar weight-average molecular masses $\left(M_{\mathrm{w}}\right)$ of $10300-10700$ or $D P_{\mathrm{w}}$ values of 38-39 (Table 2), and they had similar molecular mass distribution patterns (Fig. 7). Because the viscosity-average molecular masses $\left(M_{\mathrm{v}}\right)$ of the original regenerated and native celluloses were 110000 and 205000, respectively, or the corresponding $D P_{\mathrm{v}}$ values were 680 and 1270 , respectively (Hirota et al., 2009; Shinoda, Saito, Okita, \& Isogai, 2012), extensive depolymerization was unavoidable during the AZADO-mediated oxidation. Some oxidative cleavage of cellulose glycoside bonds owing to hydroxyl radicals and/or $\beta$-elimination may have occurred on the oxidized cellulose molecules during the AZADO-mediated oxidation under alkaline conditions in a similar manner to that of TEMPO-mediated oxidation of cellulose (Shibata \& Isogai, 2003; Isogai et al., 2011). However, neither ${ }^{13} \mathrm{C}$ NMR signals at 146 and $110 \mathrm{ppm}$ nor $\mathrm{UV}$ absorption around $235 \mathrm{~nm}$, which are due to $\mathrm{C}=\mathrm{C}$ double bonds formed by $\beta$-elimination of cellulose (Konnno, Habu, Maeda, Azuma, \& Isogai, 2006), were detected for the AZADO-oxidized regenerated cellulose, further studies are needed to make clear the detailed depolymerization mechanism of cellulose in the AZADO-mediated oxidation.

When the AZADO-oxidized regenerated cellulose was assumed to have a completely homogeneous NaTCC chemical structure, the yield was calculated to be $82 \%$ from the weight recovery ratio of $139 \%$. In a similar manner, the yield of the AZADO-oxidized native cellulose was calculated to be $66 \%$ from the weight recovery ratio of $111 \%$. In both cases, some oxidized cellulose molecules with lower molecular masses that were present in the original AZADO-oxidized celluloses may have been lost during dialysis. A dialysis membrane with a cut-off molecular mass of $\sim 5000$ was used. Because both the AZADO-oxidized celluloses had similar $M_{\mathrm{w}}$ or $M_{\mathrm{n}}$ values, the depolymerization mechanism of the AZADOmediated oxidation is not likely dependent on the original crystal structures, crystallinities, or 
molecular masses of the regenerated or native celluloses. It is, however, plausible that depolymerization occurs on the water-soluble oxidized cellulose molecules, that formed during the AZADO-mediated oxidation under homogeneous oxidation conditions.

\subsection{Reaction mechanism for the formation of NaTCC from cellulose during the AZADO- mediated oxidation}

In a previous study, the carbon-carbon cleavage reactions of 1,2-diols with the AZADO catalyst were reported and a hypervalent iodine reagent like $\mathrm{PhI}(\mathrm{OAc})_{2}$ or $\mathrm{NaIO}_{4}$ had to be used as a co-oxidant in these reactions (Shibuya, Doi, Shibuta, Uesugi, \& Iwabuchi, 2012; Shibuya, Shibuta, Fukuda, \& Iwabuchi, 2012). Thus, this is the first report showing that almost all the C2-C3 bonds of cellulose can be cleaved to form dicarboxyls in one step during AZADO $/ \mathrm{NaBr} / \mathrm{NaOCl}$ oxidation with excess $\mathrm{NaOCl}$ in water at room temperature under alkaline conditions. The important factors in the formation of NaTCC from celluloses are: 1) the use of AZADO as a catalyst, 2) the addition of excess $\mathrm{NaOCl}, 3$ ) oxidation over longer periods, and 4) the use of regenerated cellulose as a starting material. Because AZADO can oxidize primary hydroxyls and secondary hydroxyls such as the C2 and C3 hydroxyls of cellulose (Shibuya et al., 2006; Takaichi \& Isogai, 2013), two routes toward the formation of the NaTCC structure from cellulose are possible upon AZADO-mediated oxidation in water under alkaline conditions (Scheme 1). As shown in this scheme, $\mathrm{NaOCl}$ is a primary oxidant and thus the $\mathrm{C} 2-\mathrm{C} 3$ bond of cellulose is cleaved to form a dicarboxy cellulose structure during the oxidation (Whistler \& Schweiger, 1957; Floor, Kieboom, \& Bekkum, 1989). However, the oxidation mechanisms in Scheme 1 are hypothetical based on the results obtained in this study and the literature, and thus speculative at present.

\section{Conclusion}

The preparation of NaTCC or sodium mesotartarate/monohydrated glyoxilate alternating co-polyacetal with an almost homogeneous chemical structure was achieved through a onestep oxidation of regenerated cellulose using the $\mathrm{AZADO} / \mathrm{NaBr} / \mathrm{NaOCl}$ system in water at room temperature under alkaline conditions. The important factors for the preparation of NaTCC are: 1) the use of AZADO and regenerated cellulose as the catalyst and starting material, respectively, and 2) addition of excess $\mathrm{NaOCl}$ together with a longer reaction time. Thus, the AZADO-mediated oxidation brings about the cleavage of the $\mathrm{C} 2-\mathrm{C} 3$ bonds of 
cellulose and the formation of dicarboxyls other than the formation of C6-carboxyls. The yield and carboxylate content of the NaTCC prepared from the regenerated cellulose by AZADO-mediated oxidation were $82 \%$ and $10.4 \mathrm{mmol} / \mathrm{g}$, respectively, and its $D P_{\mathrm{w}}$ was 39 . Because all primary and secondary hydroxyls of regenerated cellulose can be converted to carboxyls through the one-step oxidation, the AZADO-mediated oxidation would open new fields of polysaccharide chemistry; this oxidation may be applicable to other polysaccharides to prepare new water-soluble tricarboxy polysaccharides and carboxyl-containing monomers in high yields after hydrolysis. Preparation of NaTCCs having more homogeneous chemical structures with higher molecular weights is a challenging issue to use NaTCCs as polysaccharide-based thickeners and builders in household laundry detergents.

\section{Acknowledgements}

This work was supported by the Japan Society for the Promotion of Science (JSPS) with a Grant-in-Aid for Scientific Research (Grant number 21228007).

\section{References}

Bashmakov, I. A., Dorosinets, V. A., Lukashevich, M. G., Mazanik, A. A., Tikhonova, T. F., \& Skripka, D. A. (2002). Preparation and electrical properties of cobalt-containing carbon fibers. Physics of the Solid State, 44, 1689-1697.

Floor, M., Kieboom A. P. G., \& Bekkum, V. H. (1989). Preparation and calcium complexation of oxidized polysaccharides. Part I: oxidation of maltodextrins and starch with alkaline sodium hypochlorite. Starch. 41, 348-354.

Fujisawa, S., Isogai, T., \& Isogai, A. (2010). pH and Temperature stability of cellouronic acid. Cellulose, 17, 607-615.

Head, F. S. H. (1948). Formation of tartaric acid by oxidation and hydrolysis of oxycelluloses produced by dinitrogen tetroxide. Journal of the Chemical Society, 1135-1137.

Hearon, W. M., Cheng, F. L., \& John, F. W. (1975). Chemicals from cellulose. Applied Polymer Symposium, 28, 77-84.

Heinze, T. (1998). New ionic polymers by cellulose functionalization. Macromolecular Chemistry and Physics, 199, 2341-2364.

Hiraoki, R., Fukuzumi, H., Ono, Y., Saito, T., \& Isogai, A. (2013). SEC-MALLS analysis of TEMPO-oxidized celluloses using methylation of carboxyl groups. Cellulose, in press. 
DOI: $10.1007 / \mathrm{s} 10570-013-0090-5$.

Hirota, M., Tamura, N., Saito, T., \& Isogai, A. (2009). Oxidation of regenerated cellulose with $\mathrm{NaClO}_{2}$ catalyzed by TEMPO and $\mathrm{NaClO}$ under acid-neutral conditions. Carbohydrate Polymers, 78, 330-335.

Homma, I., Isogai, T., Saito, T., \& Isogai, A. (2013). Degradation of TEMPO-oxidized cellulose fibers and nanofibrils by crude cellulase. Cellulose, 20, 795-805.

Isogai, A., \& Kato, Y. (1998). Preparation of polyuronic acid from cellulose by TEMPOmediated oxidation. Cellulose, 5, 153-164.

Isogai, A., Saito, T., \& Fukuzumi, H. (2011). TEMPO-oxidized cellulose nanofibers. Nanoscale, 3, 71-85.

Kim, U.-J., Kuga, S., Wada, M., Okano, T., \& Kondo, T. (2000). Periodate oxidation of crystalline cellulose. Biomacromolecules, 1, 488-492

Konno, N., Habu, N., Maeda, I., Azuma, N., \& Isogai, A. (2006). Cellouronate ( $\beta$-1,4-linked polyglucuronate) lyase from Brevundimonas sp. SH203: Purification and characterization. Carbohydrate Polymers, 64, 589-596.

Kurita, Y., \& Isogai, A. (2010). Reductive N-alkylation of chitosan with acetone and levulinic acid in aqueous media. International Journal of Biological Macromolecules, 47, 184-189.

Maekawa, E. \& Koshijima, T. (1990). Preparation and characterization of hydroxamic acid derivative and its metal complexes derived from cellulose. Journal of Applied Polymer Science, 40, 1601-1613.

Martina, B., Kateřina, K., Miloslava R., Jan G., \& Ruta, M. (2009). Oxycellulose: significant characteristics in relation to its pharmaceutical and medical applications. Advances in Polymer Technology, 28, 199-208.

Nevel, T. P. (1951). Oxidation of cotton cellulose by nitrogen dioxide. Journal of Textile Institute, 42, T91-T129.

Saito, T., \& Isogai, A. (2014). TEMPO-mediated oxidation of native cellulose. The effect of oxidation conditions on chemical and crystal structures of the water-insoluble fractions. Biomacromolecules, 5, 1983-1989.

Shibata, I., \& Isogai, A. (2003). Depolymerization of cellouronic acid during TEMPOmediated oxidation. Cellulose, 10, 151-158.

Shibuya, M., Doi, R., Shibuta, T., Uesugi, S., \& Iwabuchi, Y. (2012). Organocatalytic one-pot oxidative cleavage of terminal diols to dehomologated carboxylic acids. Organic Letters, 14, 5006-5009.

Shibuya, M., Shibuta, T., Fukuda, H., \& Iwabuchi, Y. (2012). Nitroxyl radical/PhI(OAc) $)_{2}$ : 
one-pot oxidative cleavage of vicinal diols to (di)carboxylic acids. Organic Letters, 14, 5010-5013.

Shibuya, M., Tomizawa, M., Suzuki, I., \& Iwabuchi, Y. (2006). 2-Azaadamantane N-oxyl (AZADO) and 1-Me-AZADO: Highly efficient organocatalysts for oxidation of alcohols. Journal of the American Chemical Society, 128, 8412-8413.

Sinha, T. J. M., \& Vasudevan, P. (1984). Blood-cellulosics interactions. Biomaterials, medical devices, and artificial organs, 12, 273-287.

Shinoda, R., Saito, T., Okita, Y., \& Isogai, A. (2010). Relationship between length and degree of polymerization of TEMPO-oxidized cellulose nanofibrils. Biomacromolecules, 13, 842-849.

Takaichi, S., \& Isogai, A. (2013). Oxidation of wood cellulose using 2-azaadamantane $N$-oxyl (AZADO) or 1-methyl-AZADO catalyst in $\mathrm{NaBr} / \mathrm{NaClO}$ system. Cellulose, 20, 19791988.

Tavernier, M. L., Delattre, C., Petit, E., \& Michaud, P. (2008). $\beta$-(1,4)-Polyglucuronic acids An overview. The Open Biotechnology Journal, 2, 73-86.

Watanabe, E., Tamura, N., Fujisawa, S., Saito, T., Habu, N., \& Isogai, A. (2013). Stability of $(1 \rightarrow 3)$-beta-polyglucuronic acid under various $\mathrm{pH}$ and temperature conditions. Carbohydrate Polymers, 97, 413-420.

Watanabe, E., Tamura, N., Saito, T., Habu, N., \& Isogai, A. (2014). Preparation of completely C6-carboxylated curdlan by catalytic oxidation with 4-acetamido-TEMPO. Carbohydrate Polymers, 100, 74-79.

Wei, F., Furihata, K., Hu F., Miyakawa, T., \& Tanokura, M. (2010). Complex mixture analysis of organic compounds in green coffee bean extract by two-dimensional NMR spectroscopy. Magnetic Resonance in chemistry, 48, 857-865.

Whistler, R. L., \& Schweiger, R. (1957). Oxidation of amylopectin with hypochlorite at different hydrogen ion concentrations. Journal of the American Chemical Society, 79, 6460-6464.

Yackel, E. C., \& Kenyon, W. O. (1942). The oxidation of cellulose by nitrogen dioxide. Journal of the American Chemical Society, 64, 131-127. 
Table 1

405 Water-solubility and ${ }^{13} \mathrm{C}-\mathrm{NMR}$ spectrum simplicity of the oxidized celluloses prepared under various conditions

407

\begin{tabular}{|c|c|c|c|}
\hline $\begin{array}{l}\text { Cellulose } \\
\text { sample }\end{array}$ & Reaction conditions & $\begin{array}{c}\text { Water } \\
\text { solubility }\end{array}$ & $\begin{array}{c}\text { Simplicity of } \\
{ }^{13} \mathrm{C}-\mathrm{NMR} \\
\text { pattern } \\
\end{array}$ \\
\hline $\begin{array}{l}\text { Regenerated } \\
\text { cellulose }\end{array}$ & Room temp., 22 h, NaOCl: 40 mmol/g-cellulose & - & Unmeasurable \\
\hline $\begin{array}{l}\text { Regenerated } \\
\text { cellulose }\end{array}$ & $\begin{array}{l}\text { Room temp., } 22 \text { h, AZADO/NaBr/NaOCl, NaOCl: } 25 \\
\text { mmol/g-cellulose }\end{array}$ & + & - \\
\hline $\begin{array}{l}\text { Regenerated } \\
\text { cellulose }\end{array}$ & $\begin{array}{l}\text { Room temp., } 6 \text { h, AZADO/NaBr/NaOCl, NaOCl: } 40 \\
\text { mmol/g-cellulose }\end{array}$ & - & Unmeasurable \\
\hline $\begin{array}{l}\text { Regenerated } \\
\text { cellulose }\end{array}$ & $\begin{array}{l}\text { Room temp., } 22 \text { h, AZADO/NaBr/NaOCl, NaOCl: } 40 \\
\text { mmol/g-cellulose }\end{array}$ & + & + \\
\hline $\begin{array}{l}\text { Native } \\
\text { cellulose }\end{array}$ & $\begin{array}{l}\text { Room temp., } 6 \text { h, AZADO/NaBr/NaOCl, NaOCl: } 10 \\
\text { mmol/g-cellulose }\end{array}$ & - & Unmeasurable \\
\hline $\begin{array}{l}\text { Native } \\
\text { cellulose }\end{array}$ & $\begin{array}{l}\text { Room temp., } 22 \text { h, AZADO/NaBr/NaOCl, NaOCl: } 40 \\
\text { mmol/g-cellulose }\end{array}$ & \pm & - \\
\hline $\begin{array}{l}\text { Native } \\
\text { cellulose }\end{array}$ & $\begin{array}{l}\text { Room temp., } 22 \text { h, AZADO/NaBr/NaOCl, NaOCl: } 45 \\
\text { mmol/g-cellulose }\end{array}$ & \pm & - \\
\hline $\begin{array}{l}\text { Native } \\
\text { cellulose }\end{array}$ & $\begin{array}{l}35^{\circ} \mathrm{C}, 22 \mathrm{~h}, \mathrm{AZADO} / \mathrm{NaBr} / \mathrm{NaOCl} \text { at } \mathrm{NaOCl}: 45^{2} \\
\text { mmol/g-cellulose }\end{array}$ & \pm & - \\
\hline $\begin{array}{l}\text { Native } \\
\text { cellulose }\end{array}$ & $\begin{array}{l}\text { Room temp., } 46 \text { h, AZADO/NaBr/NaOCl for } 2 \text { days, } \\
\mathrm{NaOCl}: 45 \mathrm{mmol} / \mathrm{g} \text {-cellulose }\end{array}$ & \pm & - \\
\hline $\begin{array}{l}\text { Native } \\
\text { cellulose }\end{array}$ & $\begin{array}{l}\text { Room temp., } 22 \mathrm{~h}, \mathrm{AZADO} / \mathrm{NaBr} / \mathrm{NaOCl}, \mathrm{NaOCl}: 25 \\
+15 \mathrm{mmol} / \mathrm{g} \text {-cellulose }\end{array}$ & \pm & \pm \\
\hline
\end{tabular}

$409{ }^{\mathrm{a}, \mathrm{b}}$ These oxidation conditions were used to prepare NaTCCs from regenerated and native 410 celluloses, respectively, in this study. 
413 Table 2

414 Weight recovery ratio, carboxylate content, weight- and number-average molecular masses $415\left(M_{\mathrm{w}}\right.$ and $M_{\mathrm{n}}$, respectively) with the corresponding degrees of polymerizations $\left(D P_{\mathrm{w}}\right.$ and $D P_{\mathrm{n}}$, 416 respectively), and polydispersity $\left(M_{\mathrm{w}} / M_{\mathrm{n}}\right)$ of the AZADO-oxidized celluloses.

417

\begin{tabular}{|c|c|c|c|c|c|c|c|}
\hline \multirow{2}{*}{$\begin{array}{l}\text { Starting } \\
\text { cellulose }\end{array}$} & \multirow{2}{*}{$\begin{array}{c}M_{\mathrm{v}}{ }^{\mathrm{a}} \\
(\mathrm{g} / \mathrm{mol}) \\
{\left[D P_{\mathrm{v}}\right]}\end{array}$} & \multirow{2}{*}{$\begin{array}{c}\text { Carboxyl } \\
\text { content } \\
(\mathrm{mmol} / \mathrm{g})^{\mathrm{a}}\end{array}$} & \multicolumn{5}{|c|}{ AZADO-oxidized product } \\
\hline & & & $\begin{array}{c}\text { Weight } \\
\text { recovery ratio } \\
(\%)\end{array}$ & $\begin{array}{l}\text { Carboxylate } \\
\text { content } \\
(\mathrm{mmol} / \mathrm{g})\end{array}$ & $\begin{array}{c}M_{\mathrm{w}} \\
(\mathrm{g} / \mathrm{mol}) \\
{\left[D P_{\mathrm{w}}\right]}\end{array}$ & $\begin{array}{c}M_{\mathrm{n}} \\
(\mathrm{g} / \mathrm{mol}) \\
{\left[D P_{\mathrm{n}}\right]}\end{array}$ & $M_{\mathrm{w}} / M_{\mathrm{n}}$ \\
\hline \multirow[t]{2}{*}{$\begin{array}{l}\text { Regenerated } \\
\text { cellulose }\end{array}$} & $\begin{array}{c}110000 \\
{[680]}\end{array}$ & 0.00 & & & & & \\
\hline & & & 139 & 10.4 & $\begin{array}{c}10700 \\
{[39]}\end{array}$ & $\begin{array}{l}6950 \\
{[26]}\end{array}$ & 1.53 \\
\hline \multirow[t]{2}{*}{$\begin{array}{l}\text { Native } \\
\text { cellulose }\end{array}$} & $\begin{array}{l}205000 \\
{[1270]}\end{array}$ & 0.01 & & & & & \\
\hline & & & 111 & 9.7 & $\begin{array}{c}10300 \\
{[38]}\end{array}$ & $\begin{array}{l}7170 \\
{[26]}\end{array}$ & 1.43 \\
\hline
\end{tabular}

$418{ }^{a}$ These data were reported in previous studies (Hirota et al., 2009; Shinoda et al., 2012). 
Fig. 1. Chemical structure of 2,3,6-tricarboxy cellulose or mesotartaric acid/monohydrated glyoxilic acid alternating co-polyacetal.

424

Fig. 2. Photos of the bleached kraft pulp slurries before (A) and after (B) AZADO-mediated

Fig. 4. ${ }^{1} \mathrm{H}$ NMR spectra of the AZADO-oxidized products prepared from the regenerated 
450

451

452

453

454

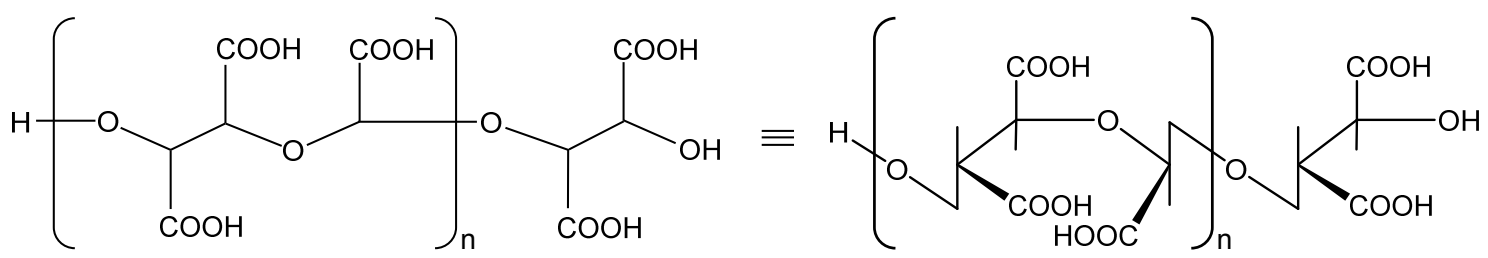

455

456

457

458

459

460

461

462

463

464

465

466

467

468

469

470

Fig. 1. Chemical structure of 2,3,6-tricarboxy cellulose or mesotartaric acid/monohydrated 479 glyoxilic acid alternating co-polyacetal. 
512 Fig. 2. Photos of the bleached kraft pulp slurries before (A) and after (B) AZADO-mediated 513 oxidation. 
Fig. 3. FT-IR spectra of regenerated cellulose (A), and AZADO-oxidized products prepared 548 
Fig. 4. ${ }^{1} \mathrm{H}$ NMR spectra of the AZADO-oxidized products prepared from the regenerated 581 and native celluloses.

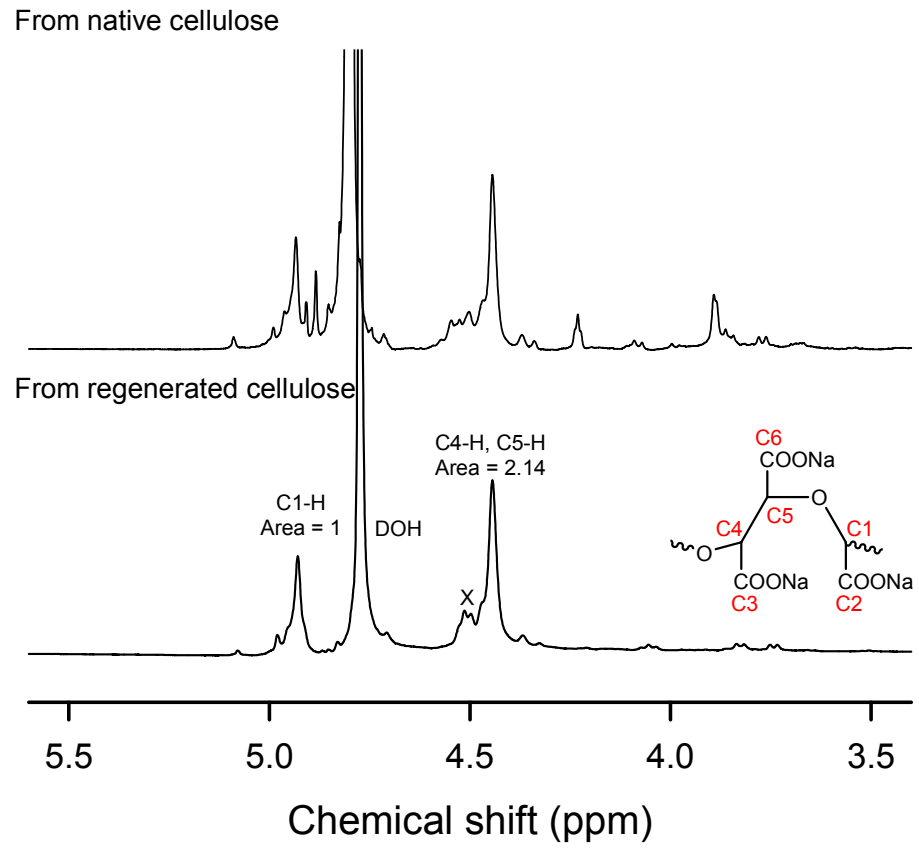


614 Fig. 5. ${ }^{13} \mathrm{C}$ NMR spectra of the AZADO-oxidized products prepared from the regenerated 615 and native celluloses, and measured using the quantitative mode.

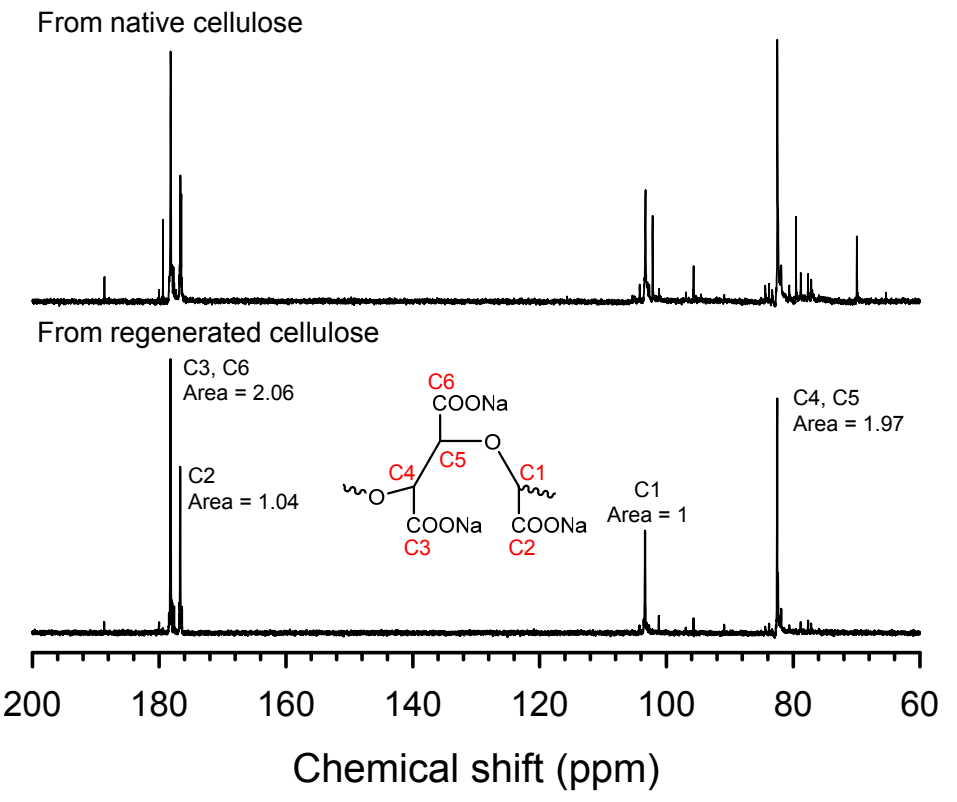


648 Fig. 6. HSQC spectrum of the AZADO-oxidized product prepared from the regenerated 649 cellulose. 


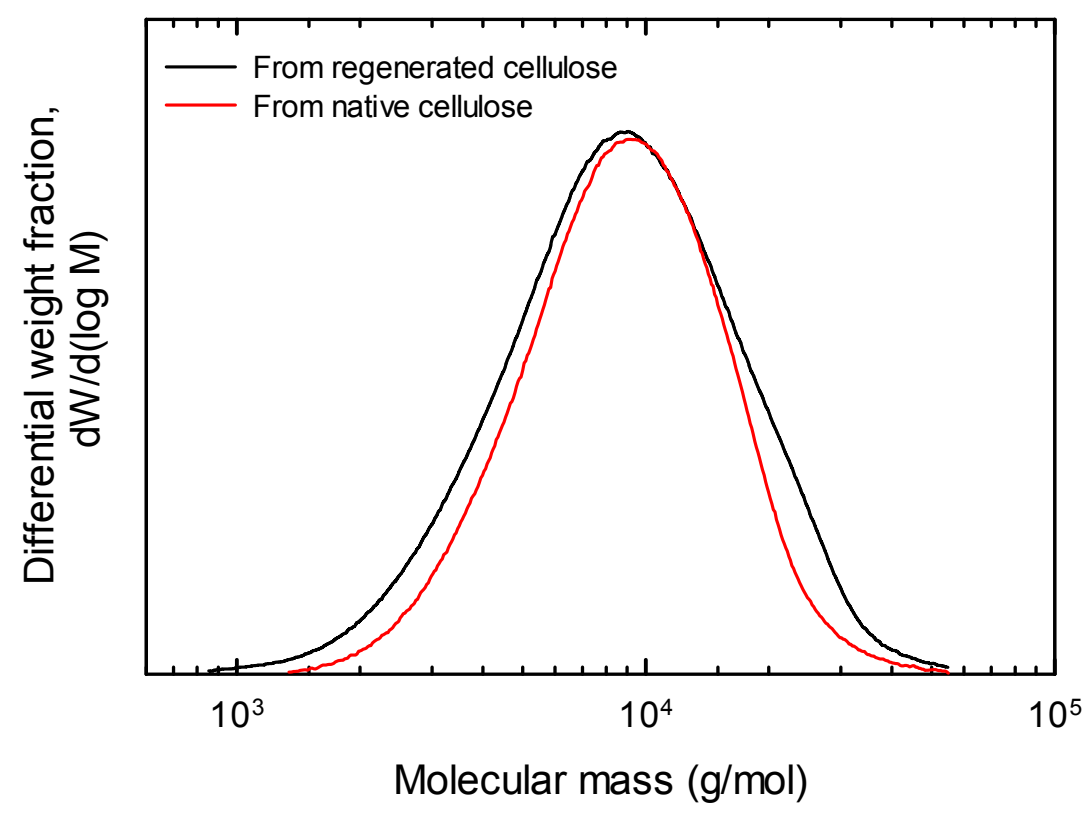

669

670

671

672

673

674

675

676

677

678

679

680

681

682

Fig. 7. Molecular mass distribution of the AZADO-oxidized products prepared from the 683 regenerated and native celluloses.

684 
688

689

690

691

692

693

694

695

696

697

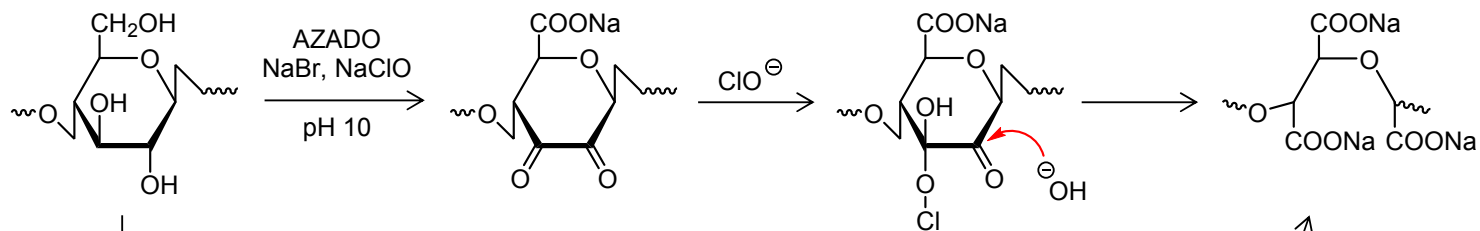

698

699

700

701

702

703

704

705

706

707

708

709

710

711

712

713

714

715 Scheme 1. Possible reaction mechanism to form NaTCC prepared from regenerated 716 cellulose by $\mathrm{AZADO} / \mathrm{NaBr} / \mathrm{NaOCl}$ oxidation. 